\title{
Magnesium Levels Modify the Effect of Lipid Parameters on Carotid Intima Media Thickness
}

\author{
Serafi Cambray ${ }^{1, *(\mathbb{D}}$, Merce Ibarz ${ }^{2}$, Marcelino Bermudez-Lopez ${ }^{1}$, Manuel Marti-Antonio ${ }^{1}$, \\ Milica Bozic ${ }^{1}$, Elvira Fernandez ${ }^{1}$, Jose M. Valdivielso 1,* $\mathbb{D}$ \\ and on behalf of the NEFRONA Investigators \\ 1 Vascular and Renal Translational Research Group, Institute for Biomedical Research Pifarré Foundation, \\ IRBLleida Av. Rovira Roure 80, 25198 Lleida, Spain; mbermudez@irblleida.cat (M.B.-L.); \\ mmartia@irblleida.cat (M.M.-A.); milica.bozic@irblleida.udl.cat (M.B.); elvirafgiraldez@gmail.com (E.F.) \\ 2 Indicators and Specifications of the Quality in the Clinical Laboratory Group, Institute for Biomedical \\ Research Pifarré Foundation, IRBLleida, 25198 Lleida, Spain; mibarz.lleida.ics@gencat.cat \\ * Correspondence: scambray@irblleida.cat (S.C.); valdivielso@irblleida.cat (J.M.V.)
}

Received: 15 July 2020; Accepted: 25 August 2020; Published: 28 August 2020

check for updates

\begin{abstract}
Classical risk factors of atherosclerosis in the general population show paradoxical effects in chronic kidney disease (CKD) patients. Thus, low low-density lipoprotein (LDL) cholesterol levels have been associated with worse cardiovascular outcomes. Magnesium (Mg) is a divalent cation whose homeostasis is altered in CKD. Furthermore, Mg levels have been associated with cardiovascular health. The present study aims to understand the relationships of $\mathrm{Mg}$ and lipid parameters with atherosclerosis in CKD. In this analysis, 1754 participants from the Observatorio Nacional de Atherosclerosis en Nefrologia (NEFRONA) cohort were included. Carotid intima media thickness (CIMT) was determined in six arterial territories, and associated factors were investigated by linear regression. cIMT correlated positively with being male, Caucasian, a smoker, diabetic, hypertensive, dyslipidemic and with increased age, BMI, and triglyceride levels, and negatively with levels of HDL cholesterol. First-order interactions in linear regression analysis showed that Mg was an effect modifier on the influence of lipidic parameters. Thus, cIMT predicted values were higher when triglycerides or LDL levels were high and Mg levels were low. On the contrary, when $\mathrm{Mg}$ levels were high, this effect disappeared. In conclusion, $\mathrm{Mg}$ acts as an effect modifier between lipidic parameters and atherosclerotic cardiovascular disease. Therefore, Mg levels, together with lipidic parameters, should be taken into account when assessing atherosclerotic risk.
\end{abstract}

Keywords: magnesium; cholesterol; atherosclerosis; first-order interaction; cardiovascular risk

\section{Introduction}

According to the Cardiovascular Disease Statistics from the European Society of Cardiology, in 2015 there were 11 million new cases of cardiovascular disease (CVD) reported in Europe, and the majority of countries showed an increase in cases from 1990 [1]. Its prevalence was reported to be 83.5 million people, of which 35.7 million people showed peripheral vascular disease [1]. Moreover, CVD also led to 64 million disability-adjusted life years in the European population [1].

Among risk factors associated with CVD, plasma lipids play a key role in the initiation and progression of atheromatous disease [2]. Epidemiological studies show that increased concentrations of low-density lipoprotein cholesterol (LDL-C) are associated with an increased risk of cardiovascular events [3,4], while the contrary effect has been demonstrated for high-density lipoprotein cholesterol [5] (HDL-C). Triglyceride levels are inversely associated with HDL-C levels [6] and, despite not showing atherogenic properties per se, are considered to be an important biomarker of CVD, due to 
their association with atherogenic remnant lipoproteins containing apo CIII [7]. Triglycerides have important implications for chronic kidney disease (CKD) patients, a population that presents a high incidence of atherosclerotic events [8]. Additionally, traditional lipid profiles are not associated with increased cardiovascular risk in this population. CKD patients present low levels of HDL-C and hypertriglyceridemia [9], but levels of LDL-C or total cholesterol are not usually modified, or are even low in advanced stages [10]. Some works point to the importance of LDL-C particle size [11] or the levels of oxidized LDL-C [12]. Nevertheless, the link between altered lipid metabolism and the higher presence of atheromasias in CKD patients is not clear.

Currently, to prevent cardiovascular events in high risk populations, most efforts have been directed towards lowering plasma LDL-C and triglycerides, by means of pharmacological treatment [13], dietary intervention [14,15], or diet supplements [16-18]. Among diet supplements, magnesium (Mg) was one of the first to be used for lowering serum lipids. During the 1980s, it was demonstrated that $\mathrm{Mg}$ deficiency was associated with hypertension and vascular calcifications, while increasing its dietary intake prevented atheroma in experimental animals with normal renal function [19], and in experimental uremia [20]. Later on, during the 1990s, different studies in patients showed that lower $\mathrm{Mg}$ plasma concentrations were associated with atherosclerosis [21], and that Mg supplementation lowered plasma cholesterol, LDL, and triglyceride concentrations [22,23]. Recent studies also found an inverse correlation between Mg levels, carotid intima-media thickness (cIMT) [24,25] and peripheral artery disease [26,27], while many epidemiological studies and clinical trials reported $\mathrm{Mg}$ as a key player in cardiovascular health [28-31], even in hemodialysis patients [32]. However, randomized clinical trials with $\mathrm{Mg}$ supplementation have yielded conflicting results [33,34]. CKD patients often present an altered $\mathrm{Mg}$ balance. Thus, the decrease in glomerular filtration rate (GFR) can induce Mg retention, whereas in other cases tubular dysfunction and diuretic use can induce hypomagnesemia. Therefore, the altered Mg levels, alongside the specific dyslipidemia found in those patients, make them a very interesting group to investigate the possible interactions of both variables in atherosclerosis.

Despite the fact that some data showed that Mg levels can affect cIMT and that, according to some studies, it could also affect plasma lipid concentrations, no studies have analyzed the possible interactions of both variables in atherosclerosis. In the present study, we aim to study the impact of $\mathrm{Mg}$ on cIMT, and how Mg interacts with plasma lipids and other known CVD risk factors in a CKD population form the Observatorio Nacional de Atherosclerosis en Nefrologia (NEFRONA) cohort.

\section{Materials and Methods}

\subsection{Study Design}

The NEFRONA study was designed to assess the utility of noninvasive vascular imaging techniques and plasma biomarkers to predict cardiovascular events and mortality in CKD patients [35,36]. Briefly, CKD and non-CKD volunteers aged 18 to 75 years were recruited throughout Spanish primary care centers and renal units from 2009 to 2012. Patients with a history of CVD, remarkable carotid stenosis, active infections (tuberculosis and human immunodeficiency virus), pregnancy, less than twelve month of life expectancy, and with any organ transplantation or carotid artery surgery were excluded from the study. Of the NEFRONA study, 1754 subjects had available serum samples to measure Mg levels. Out of those, 40 presented with missing data on CKD status or cIMT values. Thus, 1754 volunteers were used in the present study. In total, 1542 presented with CKD (629 Stage 3; 528 Stages 4-5; 385 dialysis), and 212 were non-CKD controls (glomerular filtration rate $>60 \mathrm{~mL} / \mathrm{min} / 1.73 \mathrm{~m}^{2}$ ). The ethics committee of each hospital approved the protocol of the study, and all volunteers were included after signing an informed consent. The research followed the principles of the Declaration of Helsinki. Non-CKD controls were included as per the protocol of the NEFRONA study and as a reference with normal $\mathrm{Mg}$ and lower cIMT values. 


\subsection{Clinical Data and $\mathrm{Mg}$ Determination}

A nurse and two specifically trained technicians collected the following data: gender, age, body mass index, systolic and diastolic blood pressure (SBP and DBP), pulse pressure, and smoking status. Information about presence of diabetes, hypertension, and dyslipidemia was obtained from clinical records. Fasting blood samples were also collected by the same team and were stored at $-80{ }^{\circ} \mathrm{C}$ in the Biobank of the RedInRen in the University of Alcala de Henares (Madrid). Biochemical analysis was performed as described previously [37]. The determination of $\mathrm{Mg}$ in serum samples was performed using the $\mathrm{Mg}$ reagent from Beckman Coulter (Brea, CA USA; Ref. OSR6189), following the manufacturer's instructions.

\subsection{Atherosclerosis Assessment}

Atherosclerosis assessment was performed as previously described [38]. Briefly, carotid ultrasound measurements were performed in three territories of both carotid arteries (bifurcation, internal, and common carotid arteries). Plaques were defined according to the Mannheim Carotid Intima-Media Thickness (cIMT) Consensus and the American Society of Echocardiography as a cIMT lumen protrusion $\geq 1.5 \mathrm{~mm}[39,40]$. More extended protocols and data about plaque prevalence in the entire NEFRONA cohort have been published previously [37]. In the present analysis, we used the average cIMT of the territories that did not show atheroma plaque.

\subsection{Statistical Analysis}

Absolute frequencies (and percentage) or mean (and standard deviation) were used to describe qualitative and quantitative variables, respectively. Pearson correlation coefficients were calculated to analyze the relationships between cIMT and $\mathrm{Mg}$ levels with other clinical variables. Multivariate regression linear models were used to assess the association of clinical variables with cIMT. To specifically assess the joint association of $\mathrm{Mg}$ with the rest of the explanatory variables on cIMT, all possible first-order interactions were considered in the model, and a backwards stepwise algorithm was used to select the significant ones. A graph showing the predicted values of cIMT when the rest of the variables of the model are set to zero, and showing the interactions of continuous values of lipid parameters and $\mathrm{Mg}$ levels was drawn. All analyses were performed using R, setting the threshold of significance at 0.05 .

\section{Results}

\subsection{Clinical Characteristics}

The study comprised 1754 volunteers with a mean age of $58.6 \pm 12.7$ years. Significant differences were found between CKD stages in all the parameters of the study, except in the percentage of smokers, which was not significantly different between CKD stages. Interestingly, Mg levels increased as renal function decreased, whereas cIMT levels showed the opposite tendency. LDL levels also showed a significant tendency to decrease as renal function impairment worsened (Table 1). 
Table 1. Clinical characteristics of the cohort.

\begin{tabular}{|c|c|c|c|c|c|c|c|}
\hline Variable & $\begin{array}{l}\text { All } n=1754 \\
\quad(100 \%)\end{array}$ & $\begin{array}{l}\text { Control } \\
n=212 \\
(12.1 \%)\end{array}$ & $\begin{array}{c}\text { CKD 2-3 } \\
n=629 \\
(35.9 \%)\end{array}$ & $\begin{array}{c}\text { CKD 4-5 } \\
n=528 \\
(30.1 \%)\end{array}$ & $\begin{array}{c}\text { Dialysis } \\
n=385 \\
(21.9 \%)\end{array}$ & $\begin{array}{l}p \text {-Value } \\
\text { (CKD } \\
\text { Groups) }\end{array}$ & $\begin{array}{c}p \text {-Value } \\
\text { (Trend CKD } \\
\text { Groups) }\end{array}$ \\
\hline Sex (Male) & $1040(59.3 \%)$ & $100(47.2 \%)$ & $425(67.6 \%)$ & $299(56.6 \%)$ & $216(56.1 \%)$ & $<0.001$ & 0.512 \\
\hline Race (Caucasian) & $1704(97.1 \%)$ & $209(98.6 \%)$ & $620(98.6 \%)$ & $514(97.3 \%)$ & $361(93.8 \%)$ & $<0.001$ & $<0.001$ \\
\hline Age, years & $58.6(12.7)$ & $51.7(12.4)$ & $62.15(11.2)$ & $58.8(12.5)$ & $56.4(13.6)$ & $<0.001$ & 0.001 \\
\hline Smoker (Yes) & 977 (55.7\%) & $123(58 \%)$ & $363(57.7 \%)$ & $279(52.8 \%)$ & $212(55.1 \%)$ & 0.347 & 0.211 \\
\hline Diabetes (Yes) & $373(21.3 \%)$ & $0(0 \%)$ & $170(27 \%)$ & $127(24.1 \%)$ & $76(19.7 \%)$ & $<0.001$ & 0.003 \\
\hline Hypertension (Yes) & $1498(85.4 \%)$ & 67 (31.6) & $569(90.5 \%)$ & $507(96 \%)$ & $355(92.8 \%)$ & $<0.001$ & $<0.001$ \\
\hline Dyslipidemia (Yes) & $1170(66.7 \%)$ & $52(24.5)$ & $467(74.2 \%)$ & $399(75.6 \%)$ & $252(65.5 \%)$ & $<0.001$ & $<0.001$ \\
\hline $\mathrm{BMI}\left(\mathrm{kg} / \mathrm{m}^{2}\right)$ & $28.3(5.21)$ & $27.7(4.5)$ & $29.2(4.7)$ & $28.5(5.5)$ & $26.9(5.6)$ & $<0.001$ & 0.026 \\
\hline $\mathrm{SBP}(\mathrm{mmHg})$ & $138(20.4)$ & 131 (17.9) & $138(18.7)$ & $141(18.9)$ & $138(24.8)$ & 0.004 & $<0.001$ \\
\hline DBP (mmHg) & $79.8(10.9)$ & 79 (10.2) & $79.6(9.7)$ & $81(10.2)$ & 79 (13.5) & $<0.001$ & 0.792 \\
\hline Pulse pressure (mmHg) & $58.7(16.7)$ & $52.1(12.6)$ & $58.8(15.4)$ & $60.3(16.8)$ & $59.9(19.4)$ & $<0.001$ & $<0.001$ \\
\hline Total Cholesterol (mg/dL) & $180(39.9)$ & $203(32.3)$ & $184(37.5)$ & 177 (38.5) & $164(42.2)$ & $<0.001$ & $<0.001$ \\
\hline HDL Cholesterol (mg/dL) & $50.1(14.9)$ & $52.9(13.8)$ & $50.8(14.8)$ & $50.1(15.1)$ & $46.9(15.1)$ & $<0.001$ & $<0.001$ \\
\hline LDL Cholesterol (mg/dL) & $104(34.0)$ & $127(30.2)$ & 107 (31.6) & $100(33.0)$ & $91.9(34.5)$ & $<0.001$ & $<0.001$ \\
\hline Triglycerides (mg/dL) & $141(84.6)$ & $116(71.7)$ & 145 (83.5) & $143(88.6)$ & $146(85.5)$ & $<0.001$ & $<0.001$ \\
\hline Glucose (mg/dL) & $107(42.1)$ & $96(12.4)$ & $110(38.4)$ & $107(45.1)$ & $108(52.5)$ & $<0.001$ & 0.003 \\
\hline Calcium (mmol/L) & $2.33(0.152)$ & $2.34(0.094)$ & $2.37(0.119)$ & $2.34(0.144)$ & $2.24(0.197)$ & $<0.001$ & $<0.001$ \\
\hline Phosphorus (mmol/L) & $1.259(0.332)$ & $1.09(0.158)$ & $1.06(0.18)$ & $1.292(0.245)$ & $1.55(0.442)$ & $<0.001$ & $<0.001$ \\
\hline Sodium $(\mathrm{mmol} / \mathrm{L})$ & $141(2.93)$ & $141(2.25)$ & $141(2.65)$ & $141(2.80)$ & $139(3,22)$ & $<0.001$ & $<0.001$ \\
\hline Potassium (mmol/L) & $4.79(0.60)$ & $4.4(0.39)$ & $4.7(0.50)$ & $4.9(0.54)$ & $4.9(0.80)$ & $<0.001$ & $<0.001$ \\
\hline Magnesium (mmol/L) & $0.83(0.15)$ & $0.82(0.08)$ & $0.80(0.12)$ & $0.84(0.14)$ & $0.88(0.22)$ & $<0.001$ & $<0.001$ \\
\hline cIMT & $0.73(0.14)$ & $0.70(0.13)$ & $0.75(0.14)$ & $0.71(0.14)$ & $0.72(0.14)$ & $<0.001$ & 0.569 \\
\hline
\end{tabular}

Absolute frequency (percentage) and mean (standard deviation) are shown for qualitative and quantitative variables, respectively. Abbreviations: Body Mass Index (BMI), Systolic Blood Pressure (SBP), Diastolic Blood Pressure (DBP), Carotid Intima-Media Thickness (cIMT), Chronic Kidney Disease (CKD). LDL-low-density lipoprotein; HDL-high density lipoprotein.

\subsection{Correlations of Clinical Variables with cIMT and $M g$ Levels}

Results for the correlation matrix of cIMT and Mg levels with the clinical variables of the study are shown in Table 2. cIMT correlated positively with being male, Caucasian, smoker, diabetic, hypertensive, dyslipidemic and with increased age, BMI, and triglyceride levels. Furthermore, it correlated negatively with levels of HDL cholesterol. Interestingly, no significant correlation was found with total or LDL cholesterol levels. Mg levels positively correlated with the presence of hypertension, and negatively with being Caucasian, diabetic, and with level of BMI. The correlation matrix of the variables with cIMT was calculated for the controls (Supplementary Table S1) as a sensitivity analysis. Some of the significant correlations were lost (due to the lower sample size), but most of the coefficients were similar.

Table 2. Bivariate correlation coefficients between cIMT and Magnesium levels with other variables.

\begin{tabular}{ccccc}
\hline & \multicolumn{2}{c}{ cIMT } & \multicolumn{2}{c}{ Magnesium } \\
\hline Variable & r & $p$-Value & r & $p$-Value \\
\hline Sex (Male) & 0.223 & $<0.001$ & -0.003 & 0.906 \\
\hline Race (Caucasian) & 0.083 & 0.001 & -0.079 & 0.001 \\
\hline Age, years & 0.528 & $<0.001$ & -0.035 & 0.141 \\
\hline Smoker & 0.105 & $<0.001$ & -0.018 & 0.445 \\
\hline Diabetes & 0.157 & $<0.001$ & -0.070 & 0.003 \\
\hline Hypertension & 0.137 & $<0.001$ & 0.053 & 0.028 \\
\hline Dyslipidemia & 0.094 & $<0.001$ & 0.015 & 0.536 \\
\hline BMI & 0.158 & $<0.001$ & -0.053 & 0.027 \\
\hline
\end{tabular}


Table 2. Cont.

\begin{tabular}{ccccc}
\hline & \multicolumn{2}{c}{ cIMT } & \multicolumn{2}{c}{ Magnesium } \\
\hline Variable & $\mathbf{r}$ & $\boldsymbol{p}$-Value & $\mathbf{r}$ & $\boldsymbol{p}$-Value \\
\hline Total Cholesterol & 0.021 & 0.392 & -0.043 & 0.075 \\
\hline HDL Cholesterol & -0.071 & 0.007 & 0.001 & 0.967 \\
\hline LDL Cholesterol & 0.007 & 0.781 & -0.009 & 0.724 \\
\hline Triglycerides & 0.082 & 0.001 & 0.009 & 0.709 \\
\hline Magnesium & -0.003 & 0.914 & - & - \\
\hline cIMT & - & - & -0.003 & 0.914
\end{tabular}

Pearson's correlation coefficients (r) and $p$-value are shown for each variable. Abbreviations: Body Mass Index (BMI), Carotid Intima-Media Thickness (cIMT).

\subsection{Association of Clinical Variables with cIMT}

The results from the multivariate main effects model, which included all the variables studied, showed that age, being male or a smoker, pulse pressure, potassium, and CKD stage were factors that were significantly associated with cIMT. Mg levels did not reach statistical significance in this model, underlying the fact that $\mathrm{Mg}$ had no association with cIMT when considering its effect in the multivariate model independently of the rest of variables (Table 3). However, interestingly, the results from the model including the interactions revealed that $\mathrm{Mg}$ levels were significantly associated with CIMT, when interactions with cholesterol levels (total, LDL-C, and HDL-C) and triglycerides are taken into account. Sex, age, tobacco, pulse pressure, CKD stage, and potassium levels were significantly associated with cIMT in this multivariate model (Table 4).

Table 3. Multivariate linear main effects model for cIMT.

\begin{tabular}{|c|c|c|c|}
\hline & \multicolumn{3}{|c|}{ All Cohort } \\
\hline & Beta & SE & $p$-Value \\
\hline Intercept & 0.14 & 0.18 & 0.43 \\
\hline Magnesium & 0.002 & 0.02 & 0.92 \\
\hline Sex, male & 0.034 & 0.007 & $<0.00001$ \\
\hline Race, Caucasian & 0.006 & 0.02 & 0.74 \\
\hline Age & 0.005 & 0.0003 & $<0.00001$ \\
\hline Current smoker & 0.02 & 0.007 & 0.01 \\
\hline Diabetes & -0.0002 & 0.01 & 0.98 \\
\hline Hypertension & 0.01 & 0.01 & 0.35 \\
\hline Dyslipidemia & -0.005 & 0.007 & 0.49 \\
\hline BMI & 0.0003 & 0.0007 & 0.65 \\
\hline Pulse pressure & 0.0007 & 0.0002 & 0.0004 \\
\hline CKD Stage, 2-3 & -0.03 & 0.013 & 0.015 \\
\hline CKD Stage, 4-5 & -0.06 & 0.014 & 0.00006 \\
\hline CKD Stage, dialysis & -0.016 & 0.015 & 0.31 \\
\hline Total Cholesterol & 0.0005 & 0.0004 & 0.25 \\
\hline HDL Cholesterol & -0.0006 & 0.0005 & 0.24 \\
\hline LDL Cholesterol & -0.0002 & 0.0004 & 0.57 \\
\hline Triglycerides & -0.00002 & 0.00009 & 0.82 \\
\hline Glucose & 0.0001 & 0.0001 & 0.25 \\
\hline Calcium & -0.001 & 0.006 & 0.82 \\
\hline Phosphorus & -0.002 & 0.004 & 0.59 \\
\hline Sodium & 0.0007 & 0.001 & 0.53 \\
\hline Potassium & 0.014 & 0.006 & 0.016 \\
\hline
\end{tabular}

Estimated parameters (beta), standard error (SE) and $p$-value shown for each variable. Abbreviations: Body Mass Index (BMI), Chronic Kidney Disease (CKD). 
Table 4. Multivariate linear effects model for cIMT with first-order interactions.

\begin{tabular}{|c|c|c|c|}
\hline & \multicolumn{3}{|c|}{ All Cohort } \\
\hline & Beta & SE & $p$-Value \\
\hline Intercept & 0.35 & 0.089 & 0.00007 \\
\hline Sex, male & 0.04 & 0.007 & $<0.00001$ \\
\hline Age (years) & 0.006 & 0.0003 & $<0.00001$ \\
\hline Current smoker & 0.018 & 0.007 & 0.006 \\
\hline Pulse pressure & 0.0007 & 0.0002 & 0.0002 \\
\hline CKD stage, $2-3$ & -0.027 & 0.01 & 0.01 \\
\hline CKD stage, $4-5$ & -0.05 & 0.01 & 0.00001 \\
\hline CKD stage, dialysis & -0.014 & 0.01 & 0.26 \\
\hline Magnesium & -0.12 & 0.099 & 0.23 \\
\hline Total Cholesterol & -0.006 & 0.003 & 0.02 \\
\hline HDL Cholesterol & 0.006 & 0.003 & 0.03 \\
\hline LDL Cholesterol & 0.006 & 0.003 & 0.04 \\
\hline Triglycerides & 0.001 & 0.0005 & 0.014 \\
\hline Potassium & 0.013 & 0.006 & 0.016 \\
\hline \multicolumn{4}{|l|}{ Interactions } \\
\hline Magnesium $\rightarrow$ Total Cholesterol & 0.008 & 0.003 & 0.011 \\
\hline Magnesium $\rightarrow$ HDL Cholesterol & -0.007 & 0.003 & 0.016 \\
\hline Magnesium $\rightarrow$ LDL Cholesterol & -0.007 & 0.003 & 0.03 \\
\hline Magnesium $\rightarrow$ Triglycerides & -0.0014 & 0.0005 & 0.01 \\
\hline
\end{tabular}

Estimated parameters (beta), standard error (SE) and $p$-value shown for each significant variable considering interactions.

\subsection{Visualization of the Association of the Interaction of Mg and Plasma Lipids with cIMT}

To better visualize the interactions between plasma lipids and $\mathrm{Mg}$, we performed an interaction graph for continuous data. As seen in Figure 1a, cIMT predicted values were higher when triglycerides levels were high and $\mathrm{Mg}$ levels were low. On the contrary, when $\mathrm{Mg}$ levels were higher than $1 \mathrm{mmol} / \mathrm{L}$, the relationship between high triglyceride levels and increased cIMT disappeared. A similar tendency was seen when LDL-C levels, Mg, and cIMT were plotted (Figure 1b). The interaction between HDL-C and $\mathrm{Mg}$ showed that the protective effect of high HDL-C levels disappears when Mg levels are low (Figure 1c). Finally, a paradoxical effect of total cholesterol levels is depicted, predicting higher cIMT when both total cholesterol and Mg are high (Figure 1d). 
a

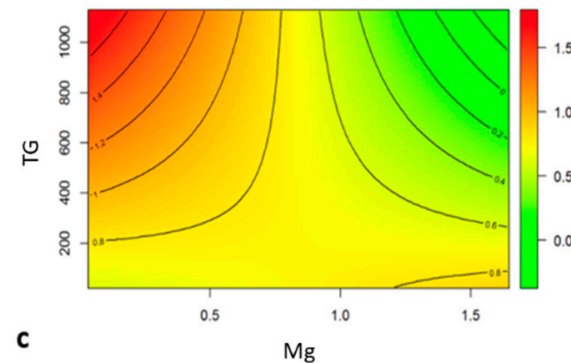

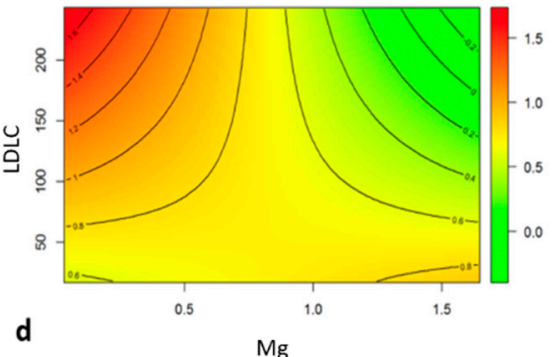
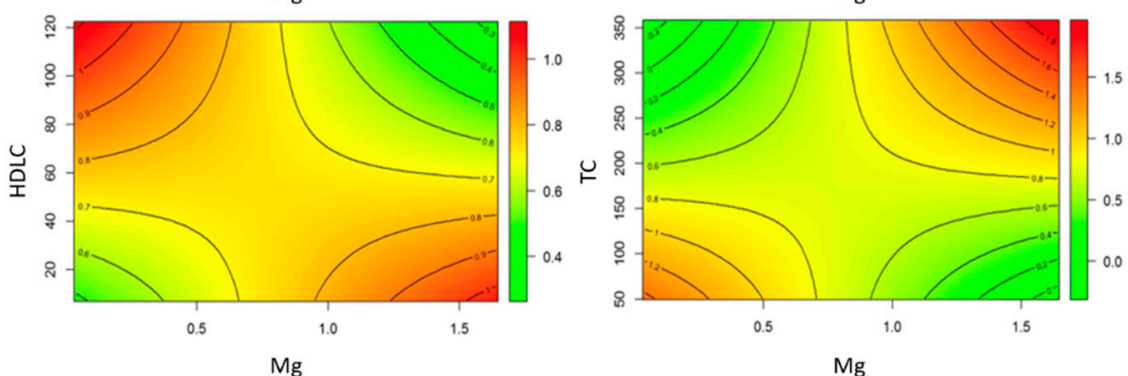

Figure 1. Interaction Graphs for Continuous Data. (a) Predicted cIMT with different levels of triglycerides (TG) and magnesium (Mg). (b) Predicted cIMT with different levels of LDL cholesterol (LDLC) and magnesium. (c) Predicted cIMT with different levels of HDL cholesterol (HDLC) and magnesium. (d) Predicted cIMT with different levels of total cholesterol (TC) and magnesium.

\section{Discussion}

The present study identifies, for the first time, the role of $\mathrm{Mg}$ as an effect modifier on the association of lipid parameters with cIMT in CKD patients. Thus, high LDL and triglyceride levels affect cIMT only when $\mathrm{Mg}$ levels are low. In the same model, high HDL levels associate with lower cIMT only when $\mathrm{Mg}$ levels are high. This result could be behind some of the paradoxical effects of lipid parameters on atherosclerosis in renal patients, in which Mg levels are often modified by the disease.

Hypertriglyceridemia and high cholesterol levels are related to atherosclerosis [2,41], and current mathematical models estimate that lipid-lowering therapies could avoid a substantial number of cardiovascular events [42]. Among the different dietary supplements proposed for lipid-lowering treatment, $\mathrm{Mg}$ has been used not only to prevent cardiovascular events in patients suffering from chronic kidney disease [43], but also for metabolic syndrome treatment [44] as well as to improve cardiovascular health in overweight and obese people [45]. In renal patients, however, the relationship between lipid parameters and atherosclerosis is not so clear. Thus, high LDL cholesterol levels have sometimes been found to be unrelated to cardiovascular disease in CKD patients. In other cases, the phenomenon called reverse causality has also been shown in this population, finding an association of lower LDL levels with higher cardiovascular risk [46]. Although malnutrition has been shown to partially explain this paradoxical effect, hypomagnesemia, which is associated with malnutrition, could be part of the exact mechanism [47]. The same different effect on cardiovascular risk has also been observed with HDL, which seems to lose its association with cardiovascular risk as renal function declines [48]. This report also shows that the interaction between $\mathrm{Mg}$ and triglycerides has an impact on cIMT. Pioneering work from the ARIC study found a relationship between serum Mg levels and cIMT that was maintained after adjusting for age, but that disappeared after adjusting for other risk factors [49]. Indeed, and in agreement with previous literature reports, $\mathrm{Mg}$ has been recently identified as a possible independent risk factor for carotid atherosclerosis [50], and a meta-analysis showed an inverse relationship between circulating and dietary $\mathrm{Mg}$ and cardiovascular risk [30]. As far as we know, none of the works that identified a relationship between serum Mg levels and cIMT have considered the impact of Mg-lipid interaction on cIMT. 
One of the possible explanations for our results is that $\mathrm{Mg}$ is an important antioxidant, and its deficiency has been related to an increase in oxidative stress biomarkers [51], and to an increase in lipid peroxidation [52,53]. High levels of these molecules have been associated with cardiovascular events [54]. A proposed mechanism of its atherogenic potential includes the recruitment and retention of macrophages, the secretion of cytokines by macrophages and endothelial cells, the proliferation of smooth muscle cells, and lymphocyte chemotaxis [55]. Therefore, according to our findings, high $\mathrm{Mg}$ levels could mitigate lipid peroxidation even with high plasma lipid profiles, thereby reducing its impact on cIMT. Another possible mechanism to explain our results could be the prevention of the oxidation of LDL by Mg. There is a clear relationship between the levels of oxidized LDL and atheromatous disease [56], and CKD patients showed increased levels of oxidized LDL [57]. In addition, it has been reported that oxidized LDL concentrations are higher in subjects with low Mg levels [58,59]. Thus, future studies should aim to correlate Mg levels with oxidized LDL levels and atheromatous disease in CKD patients. Finally, it is worth mentioning that many studies have proposed an active role of $\mathrm{Mg}$ in retarding vascular calcification of the medial arterial layer. However, this process is not related to lipid peroxidation, but to the binding of phosphate, decreasing calcium phosphate deposition [60], and regulating smooth muscle cells transdifferentiation [61].

This study has some limitations. First, its cross-sectional nature impeded us from making predictions-only associations. Furthermore, and in order to obtain a relatively wide degree of variation in $\mathrm{Mg}$ levels, a population with controls, different stages of CKD, and hemodialysis were included. This last group is especially sensible for the current analysis due to its susceptibility to present atherosclerotic disease and a plethora of additional pro-atherogenic factors (such as dialysis vintage, type of dialysis, etc.) that cannot be included in the whole analysis as possible confounders. However, CKD stage was included in the logistic model and did not reach statistical significance, allowing for the extrapolation of our results to our whole population. The second limitation is that we only measured plasma $\mathrm{Mg}$, whose levels could differ from intracellular $\mathrm{Mg}[62,63]$ (which is responsible for the majority of reactions involving it as coenzyme [31]), and from levels obtained by the twenty-four hour excretion of magnesium in urine, which could more accurately reflect $\mathrm{Mg}$ balance. However, on the one hand, plasma lipid peroxidation is the possible mechanism by which Mg could be involved in the modification of cardiovascular events [54], and therefore serum Mg levels could better correlate with cIMT than tissue levels. On the other hand, $\mathrm{Mg}$ excretion in urine should be carefully taken in CKD patients [64]; consequently, for the current study, plasma $\mathrm{Mg}$ is a valid quantification method. As for the strengths of the current work, we would like to hallmark the relatively large cohort, which allowed us to adjust the regression models by ten different variables.

In summary, the current study shows an interaction of $\mathrm{Mg}$ with lipid parameters that modifies its effect on cITM. This result could shed some light on the effect of lipid levels on atherosclerosis in conditions in which $\mathrm{Mg}$ levels are modified and highlight that the important effect of this mineral on cardiovascular physiology could be more complex than initially thought. Although this analysis suggests around $1 \mathrm{nmol} / \mathrm{L}$ as the cutoff point of serum $\mathrm{Mg}$ that could influence the deleterious effect of lipids on atherosclerosis, further specifically designed studies are needed. In conclusion, $\mathrm{Mg}$ levels should be measured together with lipid parameters in order to assess the risk of atherosclerosis, especially in situations in which alterations in serum $\mathrm{Mg}$ are expected.

Supplementary Materials: The following are available online at http://www.mdpi.com/2072-6643/12/9/2631/s1, Table S1: Bivariate correlation coefficients between cIMT and Magnesium levels with other variables in control volunteers.

Author Contributions: Conceptualization, S.C., E.F., and J.M.V.; methodology, M.I. and M.M.-A.; formal analysis, S.C., M.B.-L., and M.M.-A.; data curation, M.B.; writing-original draft preparation, S.C.; writing-review and editing, S.C. and J.M.V.; funding acquisition, E.F. and J.M.V. All authors have read and agreed to the published version of the manuscript.

Funding: This research was funded by Instituto de salud Carlos III; grants PI18/00610 and ISCIII-RETIC REDinREN RD016/009.

Conflicts of Interest: The authors declare no conflict of interest. 


\section{References}

1. Timmis, A.; Townsend, N.; Gale, C.; Grobbee, R.; Maniadakis, N.; Flather, M.; Wilkins, E.; Wright, L.; Vos, R.; Bax, J.; et al. European Society of Cardiology: Cardiovascular Disease Statistics 2017. Eur. Heart J. 2018, 39, 508-579. [CrossRef]

2. Ference, B.A.; Graham, I.; Tokgozoglu, L.; Catapano, A.L. Impact of Lipids on Cardiovascular Health: JACC Health Promotion Series. J. Am. Coll. Cardiol. 2018, 72, 1141-1156. [CrossRef] [PubMed]

3. Lewington, S.; Whitlock, G.; Clarke, R.; Sherliker, P.; Emberson, J.; Halsey, J.; Qizilbash, N.; Peto, R.; Collins, R. Blood cholesterol and vascular mortality by age, sex, and blood pressure: A meta-analysis of individual data from 61 prospective studies with 55,000 vascular deaths. Lancet 2007, 370, 1829-1839.

4. Ference, B.A.; Ginsberg, H.N.; Graham, I.; Ray, K.K.; Packard, C.J.; Bruckert, E.; Hegele, R.A.; Krauss, R.M.; Raal, F.J.; Schunkert, H.; et al. Low-density lipoproteins cause atherosclerotic cardiovascular disease. 1. Evidence from genetic, epidemiologic, and clinical studies. A consensus statement from the European Atherosclerosis Society Consensus Panel. Eur. Heart J. 2017, 38, 2459-2472. [CrossRef]

5. Toth, P.P.; Barter, P.J.; Rosenson, R.S.; Boden, W.E.; Chapman, M.J.; Cuchel, M.; D’Agostino, R.B., Sr.; Davidson, M.H.; Davidson, W.S.; Heinecke, J.W.; et al. High-density lipoproteins: A consensus statement from the National Lipid Association. J. Clin. Lipidol. 2013, 7, 484-525. [CrossRef]

6. Varbo, A.; Benn, M.; Tybjærg-Hansen, A.; Jørgensen, A.B.; Frikke-Schmidt, R.; Nordestgaard, B.G. Remnant cholesterol as a causal risk factor for ischemic heart disease. J. Am. Coll. Cardiol. 2013, 61, 427-436. [CrossRef]

7. Miller, M.; Stone, N.J.; Ballantyne, C.; Bittner, V.; Criqui, M.H.; Ginsberg, H.N.; Goldberg, A.C.; Howard, W.J.; Jacobson, M.S.; Kris-Etherton, P.M.; et al. Triglycerides and cardiovascular disease: A scientific statement from the American Heart Association. Circulation 2011, 123, 2292-2333. [CrossRef]

8. Sarnak, M.J.; Levey, A.S.; Schoolwerth, A.C.; Coresh, J.; Culleton, B.; Hamm, L.L.; McCullough, P.A.; Kasiske, B.L.; Kelepouris, E.; Klag, M.J.; et al. Kidney disease as a risk factor for development of cardiovascular disease: A statement from the American Heart Association Councils on Kidney in Cardiovascular Disease, High Blood Pressure Research, Clinical Cardiology, and Epidemiology and Prevention. Circulation 2003, 108, 2154-2169. [CrossRef]

9. Ferro, C.J.; Mark, P.B.; Kanbay, M.; Sarafidis, P.; Heine, G.H.; Rossignol, P.; Massy, Z.A.; Mallamaci, F.; Valdivielso, J.M.; Malyszko, J.; et al. Lipid management in patients with chronic kidney disease. Nat. Rev. Nephrol. 2018, 14, 727-749. [CrossRef]

10. Arroyo, D.; Betriu, A.; Martinez-Alonso, M.; Vidal, T.; Valdivielso, J.M.; Fernández, E. Observational multicenter study to evaluate the prevalence and prognosis of subclinical atheromatosis in a Spanish chronic kidney disease cohort: Baseline data from the NEFRONA study. BMC Nephrol. 2014, 15, 168. [CrossRef]

11. Bermudez-Lopez, M.; Forne, C.; Amigo, N.; Bozic, M.; Arroyo, D.; Bretones, T.; Alonso, N.; Cambray, S.; Del Pino, M.D.; Mauricio, D.; et al. An in-depth analysis shows a hidden atherogenic lipoprotein profile in non-diabetic chronic kidney disease patients. Expert Opin. Ther. Targets 2019, 23, 619-630. [CrossRef] [PubMed]

12. Florens, N.; Calzada, C.; Lyasko, E.; Juillard, L.; Soulage, C.O. Modified Lipids and Lipoproteins in Chronic Kidney Disease: A New Class of Uremic Toxins. Toxins 2016, 8, 376. [CrossRef] [PubMed]

13. Hegele, R.A.; Tsimikas, S. Lipid-Lowering Agents. Circ. Res. 2019, 124, 386-404. [CrossRef]

14. Yokoyama, Y.; Levin, S.M.; Barnard, N.D. Association between plant-based diets and plasma lipids: A systematic review and meta-analysis. Nutr. Rev. 2017, 75, 683-698. [CrossRef]

15. Schwingshackl, L.; Hoffmann, G. Comparison of effects of long-term low-fat vs high-fat diets on blood lipid levels in overweight or obese patients: A systematic review and meta-analysis. J. Acad. Nutr. Diet. 2013, 113, 1640-1661. [CrossRef]

16. Jorat, M.V.; Tabrizi, R.; Mirhosseini, N.; Lankarani, K.B.; Akbari, M.; Heydari, S.T.; Mottaghi, R.; Asemi, Z. The effects of coenzyme Q10 supplementation on lipid profiles among patients with coronary artery disease: A systematic review and meta-analysis of randomized controlled trials. Lipids Health Dis. 2018, 17, 230. [CrossRef]

17. Bianconi, V.; Mannarino, M.R.; Sahebkar, A.; Cosentino, T.; Pirro, M. Cholesterol-Lowering Nutraceuticals Affecting Vascular Function and Cardiovascular Disease Risk. Curr. Cardiol. Rep. 2018, 20, 53. [CrossRef] 
18. Martini, D.; Chiavaroli, L.; González-Sarrías, A.; Bresciani, L.; Palma-Duran, S.A.; Dall'Asta, M.; Deligiannidou, G.E.; Massaro, M.; Scoditti, E.; Combet, E.; et al. Impact of Foods and Dietary Supplements Containing Hydroxycinnamic Acids on Cardiometabolic Biomarkers: A Systematic Review to Explore Inter-Individual Variability. Nutrients 2019, 11, 1805. [CrossRef]

19. Rayssiguier, Y. Magnesium, lipids and vascular diseases. Experimental evidence in animal models. Magnesium 1986, 5, 182-190.

20. Kaesler, N.; Goettsch, C.; Weis, D.; Schurgers, L.; Hellmann, B.; Floege, J.; Kramann, R. Magnesium but not nicotinamide prevents vascular calcification in experimental uraemia. Nephrol. Dial. Transplant. 2020, 35, 65-73. [CrossRef]

21. Iskra, M.; Patelski, J.; Majewski, W. Concentrations of calcium, magnesium, zinc and copper in relation to free fatty acids and cholesterol in serum of atherosclerotic men. J. Trace Elem. Electrolytes Health Dis. 1993, 7, 185-188.

22. Kirsten, R.; Heintz, B.; Nelson, K.; Sieberth, H.G.; Oremek, G.; Hasford, J.; Speck, U. Magnesium pyridoxal 5-phosphate glutamate reduces hyperlipidaemia in patients with chronic renal insufficiency. Eur. J. Clin. Pharmacol. 1988, 34, 133-137. [CrossRef]

23. Singh, R.B.; Rastogi, S.S.; Mani, U.V.; Seth, J.; Devi, L. Does dietary magnesium modulate blood lipids? Biol. Trace Elem. Res. 1991, 30, 59-64. [CrossRef]

24. De Oliveira Otto, M.C.; Alonso, A.; Lee, D.H.; Delclos, G.L.; Jenny, N.S.; Jiang, R.; Lima, J.A.; Symanski, E.; Jacobs, D.R., Jr.; Nettleton, J.A. Dietary micronutrient intakes are associated with markers of inflammation but not with markers of subclinical atherosclerosis. J. Nutr. 2011, 141, 1508-1515. [CrossRef]

25. Hashimoto, T.; Hara, A.; Ohkubo, T.; Kikuya, M.; Shintani, Y.; Metoki, H.; Inoue, R.; Asayama, K.; Kanno, A.; Nakashita, M.; et al. Serum magnesium, ambulatory blood pressure, and carotid artery alteration: The Ohasama study. Am. J. Hypertens. 2010, 23, 1292-1298. [CrossRef]

26. Sun, X.; Zhuang, X.; Huo, M.; Feng, P.; Zhang, S.; Zhong, X.; Zhou, H.; Guo, Y.; Hu, X.; Du, Z.; et al. Serum magnesium and the prevalence of peripheral artery disease: The Atherosclerosis Risk in Communities (ARIC) study. Atherosclerosis 2019, 282, 196-201. [CrossRef]

27. Menez, S.; Ding, N.; Grams, M.E.; Lutsey, P.L.; Heiss, G.; Folsom, A.R.; Selvin, E.; Coresh, J.; Jaar, B.G.; Matsushita, K. Serum magnesium, bone-mineral metabolism markers and their interactions with kidney function on subsequent risk of peripheral artery disease: The Atherosclerosis Risk in Communities Study. Nephrol. Dial. Transplant. 2020. [CrossRef]

28. Rosique-Esteban, N.; Guasch-Ferré, M.; Hernández-Alonso, P.; Salas-Salvadó, J. Dietary Magnesium and Cardiovascular Disease: A Review with Emphasis in Epidemiological Studies. Nutrients 2018, 10, 168. [CrossRef]

29. DiNicolantonio, J.J.; Liu, J.; O'Keefe, J.H. Magnesium for the prevention and treatment of cardiovascular disease. Open Heart 2018, 5, e000775. [CrossRef]

30. Del Gobbo, L.C.; Imamura, F.; Wu, J.H.; de Oliveira Otto, M.C.; Chiuve, S.E.; Mozaffarian, D. Circulating and dietary magnesium and risk of cardiovascular disease: A systematic review and meta-analysis of prospective studies. Am. J. Clin. Nutr. 2013, 98, 160-173. [CrossRef]

31. Severino, P.; Netti, L.; Mariani, M.V.; Maraone, A.; D’Amato, A.; Scarpati, R.; Infusino, F.; Pucci, M.; Lavalle, C.; Maestrini, V.; et al. Prevention of Cardiovascular Disease: Screening for Magnesium Deficiency. Cardiol. Res. Pract. 2019, 2019, 4874921. [CrossRef]

32. Tzanakis, I.P.; Stamataki, E.E.; Papadaki, A.N.; Giannakis, N.; Damianakis, N.E.; Oreopoulos, D.G. Magnesium retards the progress of the arterial calcifications in hemodialysis patients: A pilot study. Int. Urol. Nephrol. 2014, 46, 2199-2205. [CrossRef]

33. Woods, K.L.; Fletcher, S.; Roffe, C.; Haider, Y. Intravenous magnesium sulphate in suspected acute myocardial infarction: Results of the second Leicester Intravenous Magnesium Intervention Trial (LIMIT-2). Lancet 1992, 339, 1553-1558. [CrossRef]

34. ISIS-4. A randomised factorial trial assessing early oral captopril, oral mononitrate, and intravenous magnesium sulphate in 58,050 patients with suspected acute myocardial infarction. ISIS-4 (Fourth International Study of Infarct Survival) Collaborative Group. Lancet 1995, 345, 669-685. [CrossRef] 
35. Junyent, M.; Martínez Alonso, M.; Borràs, M.; Betriu i Bars, M.; Coll, B.; Marco Mayayo, M.P.; Sarró, F.; Valdivielso Revilla, J.M.; Fernández i Giráldez, E. Usefulness of imaging techniques and novel biomarkers in the prediction of cardiovascular risk in patients with chronic kidney disease in Spain: The NEFRONA project. Nefrologia 2010, 30, 119-126.

36. Junyent, M.; Martínez, M.; Borràs, M.; Coll, B.; Valdivielso, J.M.; Vidal, T.; Sarró, F.; Roig, J.; Craver, L.; Fernández, E. Predicting cardiovascular disease morbidity and mortality in chronic kidney disease in Spain. The rationale and design of NEFRONA: A prospective, multicenter, observational cohort study. BMC Nephrol. 2010, 11, 14. [CrossRef]

37. Betriu, A.; Martinez-Alonso, M.; Arcidiacono, M.V.; Cannata-Andia, J.; Pascual, J.; Valdivielso, J.M.; Fernández, E. Prevalence of subclinical atheromatosis and associated risk factors in chronic kidney disease: The NEFRONA study. Nephrol. Dial. Transplant. 2014, 29, 1415-1422. [CrossRef]

38. Gracia, M.; Betriu, À.; Martínez-Alonso, M.; Arroyo, D.; Abajo, M.; Fernández, E.; Valdivielso, J.M. Predictors of Subclinical Atheromatosis Progression over 2 Years in Patients with Different Stages of CKD. Clin. J. Am. Soc. Nephrol. 2016, 11, 287-296. [CrossRef]

39. Stein, J.H.; Korcarz, C.E.; Hurst, R.T.; Lonn, E.; Kendall, C.B.; Mohler, E.R.; Najjar, S.S.; Rembold, C.M.; Post, W.S. Use of carotid ultrasound to identify subclinical vascular disease and evaluate cardiovascular disease risk: A consensus statement from the American Society of Echocardiography Carotid Intima-Media Thickness Task Force. Endorsed by the Society for Vascular Medicine. J. Am. Soc. Echocardiogr. 2008, 21, 93-111.

40. Touboul, P.J.; Hennerici, M.G.; Meairs, S.; Adams, H.; Amarenco, P.; Desvarieux, M.; Ebrahim, S.; Fatar, M.; Hernandez, R.H.; Kownator, S.; et al. Mannheim intima-media thickness consensus. Cerebrovasc. Dis. 2004, 18, 346-349. [CrossRef]

41. Peng, J.; Luo, F.; Ruan, G.; Peng, R.; Li, X. Hypertriglyceridemia and atherosclerosis. Lipids Health Dis. 2017, 16, 233. [CrossRef] [PubMed]

42. Cannon, C.P.; Khan, I.; Klimchak, A.C.; Sanchez, R.J.; Sasiela, W.J.; Massaro, J.M.; D’Agostino, R.B.; Reynolds, M.R. Simulation of impact on cardiovascular events due to lipid-lowering therapy intensification in a population with atherosclerotic cardiovascular disease. Am. Heart J. 2019, 216, 30-41. [CrossRef]

43. Leenders, N.H.J.; Vervloet, M.G. Magnesium: A Magic Bullet for Cardiovascular Disease in Chronic Kidney Disease? Nutrients 2019, 11, 455. [CrossRef]

44. Guerrero-Romero, F.; Jaquez-Chairez, F.O.; Rodríguez-Morán, M. Magnesium in metabolic syndrome: A review based on randomized, double-blind clinical trials. Magnes. Res. 2016, 29, 146-153. [CrossRef] [PubMed]

45. Joris, P.J.; Plat, J.; Bakker, S.J.; Mensink, R.P. Long-term magnesium supplementation improves arterial stiffness in overweight and obese adults: Results of a randomized, double-blind, placebo-controlled intervention trial. Am. J. Clin. Nutr. 2016, 103, 1260-1266. [CrossRef]

46. Massy, Z.A.; de Zeeuw, D. LDL cholesterol in CKD-to treat or not to treat? Kidney Int. 2013, 84, 451-456. [CrossRef]

47. Jahnen-Dechent, W.; Ketteler, M. Magnesium basics. Clin. Kidney J. 2012, 5 (Suppl. 1), i3-i14. [CrossRef]

48. Zewinger, S.; Speer, T.; Kleber, M.E.; Scharnagl, H.; Woitas, R.; Lepper, P.M.; Pfahler, K.; Seiler, S.; Heine, G.H.; März, W.; et al. HDL cholesterol is not associated with lower mortality in patients with kidney dysfunction. J. Am. Soc. Nephrol. 2014, 25, 1073-1082. [CrossRef]

49. Ma, J.; Folsom, A.R.; Melnick, S.L.; Eckfeldt, J.H.; Sharrett, A.R.; Nabulsi, A.A.; Hutchinson, R.G.; Metcalf, P.A. Associations of serum and dietary magnesium with cardiovascular disease, hypertension, diabetes, insulin, and carotid arterial wall thickness: The ARIC study. Atherosclerosis Risk in Communities Study. J. Clin. Epidemiol. 1995, 48, 927-940. [CrossRef]

50. Rodríguez-Ortiz, M.E.; Gómez-Delgado, F.; de Larriva, A.P.A.; Canalejo, A.; Gómez-Luna, P.; Herencia, C.; López-Moreno, J.; Rodríguez, M.; López-Miranda, J.; Almadén, Y. Serum Magnesium is associated with Carotid Atherosclerosis in patients with high cardiovascular risk (CORDIOPREV Study). Sci. Rep. 2019, 9, 8013. [CrossRef]

51. Zheltova, A.A.; Kharitonova, M.V.; Iezhitsa, I.N.; Spasov, A.A. Magnesium deficiency and oxidative stress: An update. Biomedicine 2016, 6, 20. [CrossRef] [PubMed]

52. Rayssiguier, Y.; Gueux, E.; Bussière, L.; Durlach, J.; Mazur, A. Dietary magnesium affects susceptibility of lipoproteins and tissues to peroxidation in rats. J. Am. Coll. Nutr. 1993, 12, 133-137. [CrossRef] [PubMed] 
53. Scibior, A.; Gołębiowska, D.; Niedźwiecka, I. Magnesium can protect against vanadium-induced lipid peroxidation in the hepatic tissue. Oxid. Med. Cell. Longev. 2013, 2013, 802734. [CrossRef] [PubMed]

54. Walter, M.F.; Jacob, R.F.; Bjork, R.E.; Jeffers, B.; Buch, J.; Mizuno, Y.; Mason, R.P. Circulating lipid hydroperoxides predict cardiovascular events in patients with stable coronary artery disease: The PREVENT study. J. Am. Coll. Cardiol. 2008, 51, 1196-1202. [CrossRef]

55. Feingold, K.R.; Grunfeld, C. Introduction to Lipids and Lipoproteins. In Endotext; Feingold, K.R., Anawalt, B., Boyce, A., Eds.; MDText.com, Inc.: South Dartmouth, MA, USA, 2 February 2018.

56. Gao, S.; Liu, J. Association between circulating oxidized low-density lipoprotein and atherosclerotic cardiovascular disease. Chronic Dis. Transl. Med. 2017, 3, 89-94. [CrossRef]

57. Vaziri, N.D. Role of dyslipidemia in impairment of energy metabolism, oxidative stress, inflammation and cardiovascular disease in chronic kidney disease. Clin. Exp. Nephrol. 2014, 18, 265-268. [CrossRef]

58. Cocate, P.G.; Natali, A.J.; de Oliveira, A.; Longo, G.Z.; Rita de Cássia, G.A.; Maria do Carmo, G.P.; dos Santos, E.C.; Buthers, J.M.; de Oliveira, L.L.; Hermsdorff, H.H.M. Fruit and vegetable intake and related nutrients are associated with oxidative stress markers in middle-aged men. Nutrition 2014, 30, 660-665. [CrossRef]

59. Wegner, M.; Araszkiewicz, A.; Zozulińska-Ziółkiewicz, D.; Wierusz-Wysocka, B.; Pioruńska-Mikołajczak, A.; Pioruńska-Stolzmann, M. The relationship between concentrations of magnesium and oxidized low density lipoprotein and the activity of platelet activating factor acetylhydrolase in the serum of patients with type 1 diabetes. Magnes. Res. 2010, 23, 97-104.

60. Louvet, L.; Büchel, J.; Steppan, S.; Passlick-Deetjen, J.; Massy, Z.A. Magnesium prevents phosphate-induced calcification in human aortic vascular smooth muscle cells. Nephrol. Dial. Transplant. 2013, 28, 869-878. [CrossRef]

61. Braake, A.D.; Shanahan, C.M.; Baaij, J.F.H. Magnesium Counteracts Vascular Calcification Passive Interference or Active Modulation? Arterioscler. Thromb. Vasc. Biol. 2017, 37, 1431-1445. [CrossRef]

62. De Lourdes Lima, M.; Cruz, T.; Rodrigues, L.E.; Bomfim, O.; Melo, J.; Correia, R.; Porto, M.; Cedro, A.; Vicente, E. Serum and intracellular magnesium deficiency in patients with metabolic syndrome-Evidences for its relation to insulin resistance. Diabetes Res. Clin. Pract. 2009, 83, 257-262. [CrossRef] [PubMed]

63. Shah, S.A.; Clyne, C.A.; Henyan, N.; Migeed, M.; Yarlagadda, R.; Silver, B.B.; Kluger, J.; White, C.M. Impact of magnesium sulfate on serum magnesium concentrations and intracellular electrolyte concentrations among patients undergoing radio frequency catheter ablation. Conn. Med. 2008, 72, 261-265. [PubMed]

64. Elin, J.R. Assessment of magnessium status for diagnosis and therapy. Magnes. Res. 2010, 23, $194-198$. 